\title{
Pathology of Tumors in Animals
}

National Cancer Institute

\section{Source}

National Cancer Institute. Pathology of Tumors in Animals. NCI Thesaurus. Code C18927.

A branch of pathology that focuses on animal tumors. 